\title{
Estimation of Seismic Earth Pressures Against Rigid Retaining Structures with Rotation Mode
}

\author{
Fei Song ${ }^{1, *}$ and Jian-Min Zhang ${ }^{2}$ \\ ${ }^{I}$ School of Highway Engineering, Chang'an University, 710064, Xi'an, China \\ ${ }^{2}$ Department of Hydroelectric Engineering, Tsinghua University, 100084, Beijing, China
}

\begin{abstract}
The evaluation of seismic earth pressures is of vital importance for the earthquake resistant design of various retaining walls and infrastructures. It is one of the key research subjects in soil mechanics and geotechnical engineering. In engineering practices, the magnitude and distribution of seismic earth pressures are greatly affected by the mode and amount of wall displacement. However, classic Mononobe-Okabe solution can only compute the seismic earth pressures at the limit state and doesn't consider the effect of the mode and amount of wall movement on the seismic earth pressure. In this paper, the formation mechanism of earth pressures against rigid retaining wall with RTT and RBT mode is revealed based on the previous studies and a new method is proposed to calculate the seismic earth pressures in such conditions. Corresponding formula are derived and computer code is written to calculate the seismic earth pressure distribution based on the proposed methodology. Variation of seismic earth pressure coefficient for the rigid retaining wall with RTT and RBT mode is calculated and discussed. In addition, the effectiveness of the method is confirmed by the experimental results.
\end{abstract}

Keywords: Seismic earth pressures, rotation mode, wall displacement, formation mechanism, calculation method.

\section{INTRODUCTION}

Earth retaining structures such as retaining walls, sheet pile bulkheads, cofferdams, bridge abutments and basement walls are widely used in civil engineering. Estimation of seismic earth pressures is very important for the earthquake resistant design of such retaining structures. Pseudo-static analysis based on the Mononobe-Okabe solution is most widely used in engineering practices for earthquake resistant design due to its advantage of simplicity. However, it can only compute the seismic earth pressures at the limit state and doesn't consider the effect of the mode and magnitude of wall movement on the seismic earth pressures. While earth pressures may fall anywhere between the active and passive state and are closely related to the wall displacement mode especially for seismic conditions. Model test results of Terzaghi (1934), Matsuo et al. (1941, 1960\&1978), Ishii et al. (1960), Ichihara et al. (1973), Fang et al. (1986\&1994) and Ishibashi et al. (1987) all indicate that the magnitude and distribution of earth pressure against retaining walls are closely related to the mode and amount of wall displacement [1-9]. In engineering practices, the movement mode of rotation about a point above the top of the wall (RTT) takes place in some retaining structures such as bridge abutments. While for some retaining structures whose bottoms are restrained such as the cantilever retaining wall, the movement mode of rotation about a point under the bottom

*Address correspondence to this author at the Institute of Geotechnical Engineering, School of Highway Engineering, Chang'an University, Xi'an 710064, China; Tel: +86-13572924667; Fax: +86-029-82334434;

E-mail: songfei05@tsinghua.org.cn of the wall (RBT) will take place. The backfill at different depth along the wall is under different lateral strain constraint and cannot reach the limit state at the same time for the retaining structures with RTT and RBT mode. Methods to evaluate earth pressures against rigid retaining structures under RB and RT mode have been proposed by some researchers such as Dubrova (1963), Chang (1997) and Gong et al. (2005\&2006) [10-13]. However, the relation between the mobilized frictional angle and the wall displacement proposed by them is empirical. And test results indicate that a unique relation does not exist between the earth pressure coefficient and the wall displacement [14]. Zhang et al. (1998) conducted strain path tests controlled under different strain increment ratios and established the relation between the mobilized frictional angle and the strain increment ratio based on the analysis of the test results. On this basis they developed a new theory for determining the lateral earth pressure under any lateral deformation between active and passive states. By employing the concept "intermediate soil wedge" which depends on mobilized frictional resistance, Zhang et al. (1998) extended Mononobe-Okabe method to new earth pressure formulas for determining the dynamic earth pressure under any lateral deformation $[14,15]$. The method has undoubted theoretical basis and clear physical concepts and is easy for application because of its simplicity. However, the characteristic of nonlinear distribution of seismic earth pressure against retaining structures with RTT mode is not fully considered. Besides, the formulas for the earth pressure distribution under rotation mode are complicated and not convenient for use. 
In this paper, the formation mechanism of earth pressures against rigid retaining structures under rotation mode is analyzed and revealed based on the study of Zhang et al. (1998). The characteristic of nonlinear distribution of seismic earth pressures is well taken into account by employing the method of horizontal differential element. On this basis, a new method is developed for the evaluation of seismic earth pressure against rigid retaining structures with RTT mode. In addition, by employing the concept of intermediate soil wedge and mobilized friction angle, simple formula are derived for the calculation of seismic earth pressure distribution for rigid retaining wall with RTT and RBT mode. A chart for the seismic earth pressure coefficients is given based on the calculation results by the method developed. Furthermore, the effectiveness of the proposed method is confirmed by the experimental results of Fang et al. (1986 and 1987).

\section{FORMATION MECHANISM OF EARTH PRESSURES AGAINST WALLS UNDER ROTATION MODE}

Zhang et al. (1998) pointed that the wall movement actually results in the variation of the lateral strain constraint of the backfill behind the wall, which in turn causes the change of the earth pressures acting against the wall [14]. Therefore, the ratio of minor to major principal strain increments, defined as $R \varepsilon=\triangle \varepsilon_{3} / \triangle \varepsilon_{1}$, can be employed to express the lateral strain constraint of the backfill. Zhang et al. (1998) conducted a series of strain path tests under different constant strain increment ratios to measure earth pressure coefficients of soil under different lateral strain constraints. On the basis of the analysis of the results of constant strain increment ratio path tests, they found out that the compression-dilatancy coupling effect is responsible for the dependency of the change of the earth pressure on the strain increment ratio and also the lateral strain constraint of the backfill, which is shown in Fig. (1). As can be seen in Fig (1), when the amount of wall displacement is zero, $R \varepsilon=\triangle \varepsilon_{3} / \triangle \varepsilon_{1}=0$. The backfill is at $K_{0}$ state and the friction resistance is partly mobilized. At this time the soil has both compression effect and the stress-dilatancy effect and the earth pressure coefficient is $K_{0}$. With the wall moving away from the backfill, the lateral extension and vertical settlement take place in the soil and $R_{\varepsilon}$ decreases. From the $K_{0}$ state to the active state, $0>R_{\varepsilon}>-1$ and the shear deformation of the soil keeps developing with the reduction of $R_{\varepsilon}$. The compression effect gradually decreases and the stressdilatancy effect increases. And the mobilized friction angle increases at the same time. When the wall displacement is large enough, resulting in $R_{\varepsilon}=-1$, the soil reaches the shear failure state, i.e., the active state. The friction resistance is fully mobilized and the mobilized friction angle reaches its maximum value, i.e., $\varphi^{\prime}$. At this time, the soil has only stressdilatancy effect.

Furthermore, based on the analysis of constant strain increment ratio path test results, Zhang et al. (1998) established the unique relation between the earth pressure coefficient and the strain increment ratio, which is expressed by the following equation [14]:

$\left(\frac{\sigma_{3}^{\prime}}{\sigma_{1}^{\prime}}\right)_{\min }=\frac{1-\sin \varphi^{\prime}}{1-\sin \varphi^{\prime} \cdot R_{\varepsilon}}$

in which $R_{\varepsilon}=\Delta \varepsilon_{3} / \Delta \varepsilon_{1}$ and $\varphi^{\prime}$ value is determined by triaxial drained compression tests.

It is pointed out that a unique relation exists between the earth pressure coefficient and the lateral strain constraint between active and passive states. But it does not exist between the earth pressure coefficient and the wall displacement. Based on Eq. (1) and Mohr-Coulomb's criterion, Zhang et al. (1998) proposed the following equation to determine the relation between mobilized friction angle and the strain increment ratio [14]:

$\sin \varphi_{m o b}^{\prime}=\frac{\sin \varphi^{\prime}\left(1-R_{\varepsilon}\right)}{2-\sin \varphi^{\prime}\left(1+R_{\varepsilon}\right)}$

It can be seen from equation (2) that when $R_{\varepsilon}=1, \varphi_{\text {mob }}^{\prime}=0$. At this time, the soil is at isotropic compression state and has only compression effect. The mobilized shear strength is

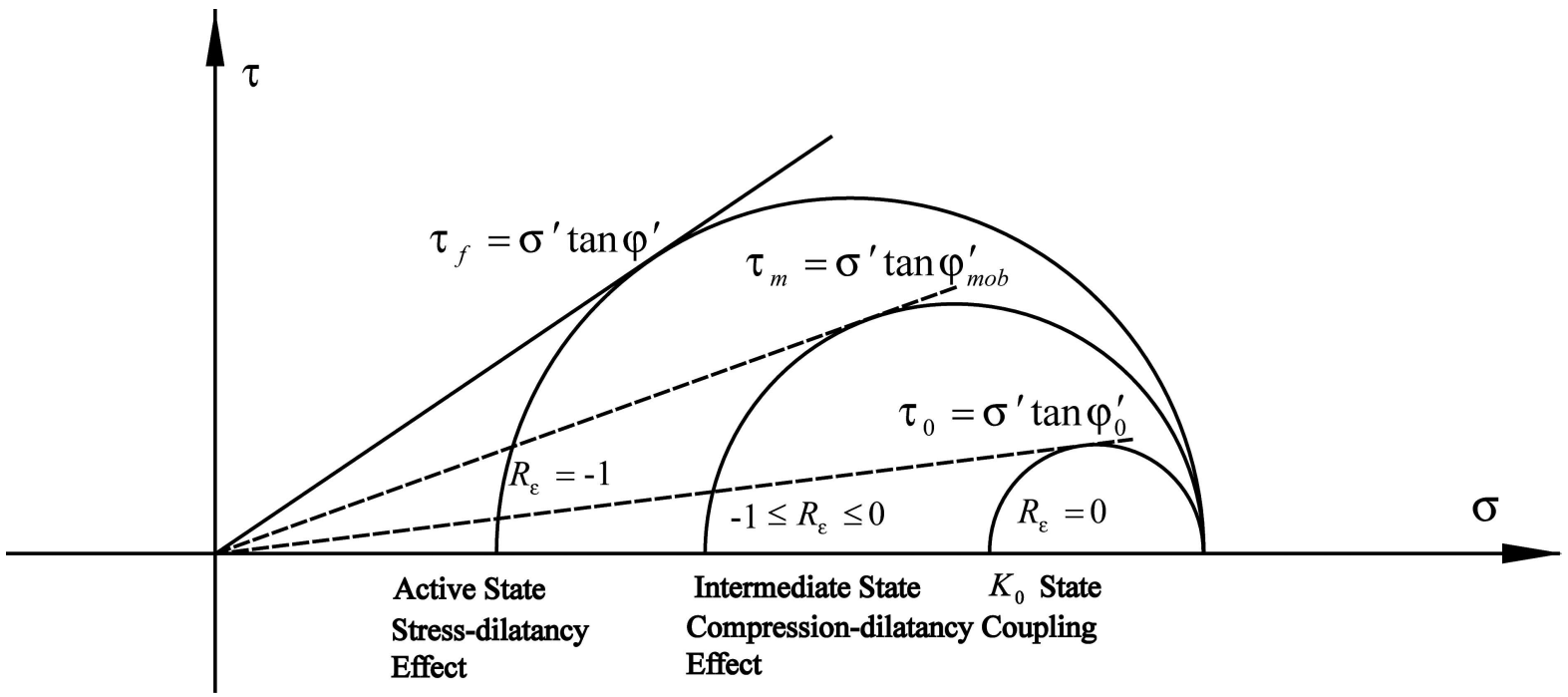

Fig. (1). Formation mechanism of earth pressure at the active side. 
zero. When $R_{\varepsilon}=-1, \varphi^{\prime}{ }_{\mathrm{mob}}=\varphi^{\prime}$. At this time, the soil is at shear failure state and has only stress-dilatancy effect. The mobilized shear strength reaches the maximum value. The mobilized shear strength under different lateral strain constraints is dependant on different levels of compressiondilatancy coupling effect.

For the rotation mode of wall movement, the amount of wall displacement is different along the wall. So the backfill is at different lateral strain constraint. The compression effect and stress-dilatancy effect of the backfill vary at different depths. With the increase of the rotation angle, the backfill near the lower part of the wall firstly reaches the limit state, and then the backfill at the upper part gradually reaches the limit state. At the active side, $R_{\varepsilon}=\triangle \varepsilon_{3} / \triangle \varepsilon_{1}=\triangle \varepsilon_{\mathrm{r}} / \triangle \varepsilon_{\mathrm{a}}$, in which $\triangle \varepsilon_{\mathrm{r}}$ and $\triangle \varepsilon_{\mathrm{a}}$ are the lateral and axial strain increments respectively. The schematic diagram of mobilization of internal friction angle and wall friction angle are illustrated in Fig. (2).
In Fig. (2), $\triangle_{\mathrm{z}}$ and $\triangle_{\mathrm{a}}$ are used to denote the amount of wall displacement at certain depth $\mathrm{z}$ and required to reach the active state respectively. $\theta$ is the rotational angle of the wall away from the wall. $\triangle_{\mathrm{z}}$ is prescribed minus when its direction is away from the backfill. It can be seen from Fig. (2a) that for the RTT mode, the amount of wall displacement at the top of the wall is smaller than the bottom of the wall. Therefore, the lateral deformation of the backfill near the top of the wall is also smaller than that at the lower part of the backfill. With the increase of the depth of the backfill, the proportion of compression deformation in the total deformation gradually decreases and that of shear deformation gradually increases, meaning that compression effect decreases and stress-dilatancy effect increases. The mobilized frictional resistance gradually increases with the backfill depth and the one at the lower part of the backfill is larger than that of the upper part of the backfill. When $-\triangle_{\mathrm{a}}\left\langle\triangle_{\mathrm{z}} \leq 0,0>R_{\varepsilon}>-1\right.$, and soil elements have both compression and stress-dilatancy effect. The proportion of deformation due to compression and that

wall movement

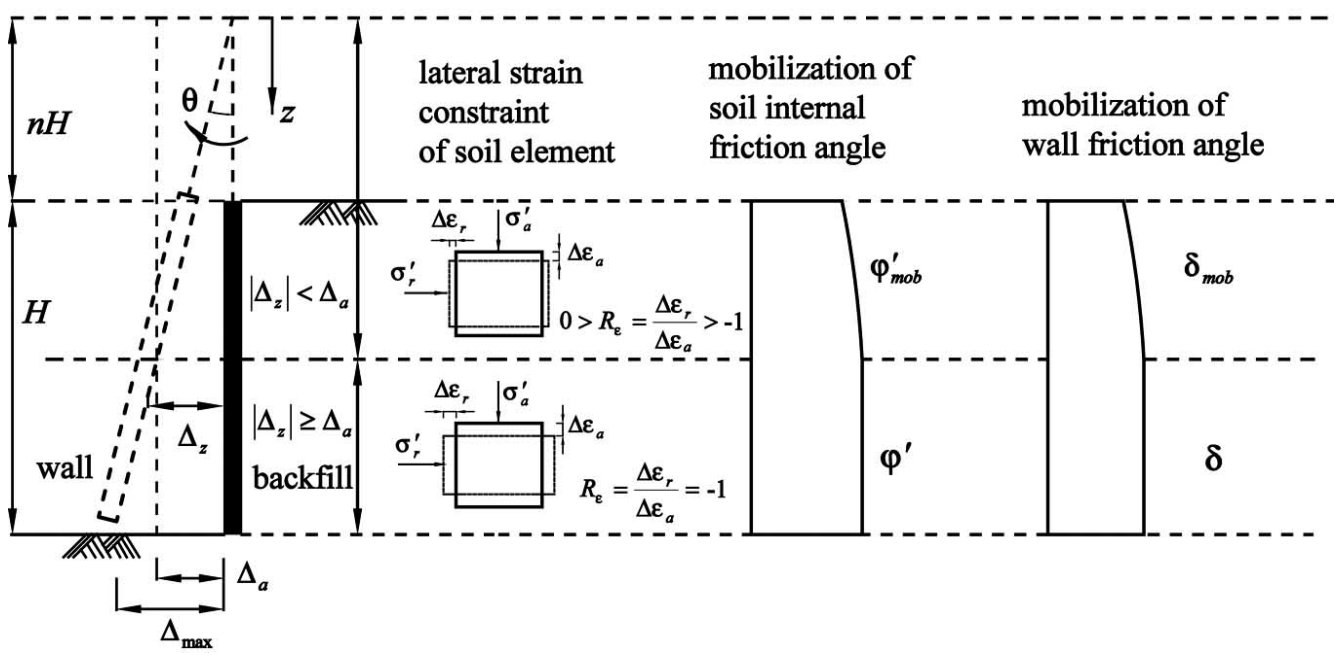

(a) RTT mode

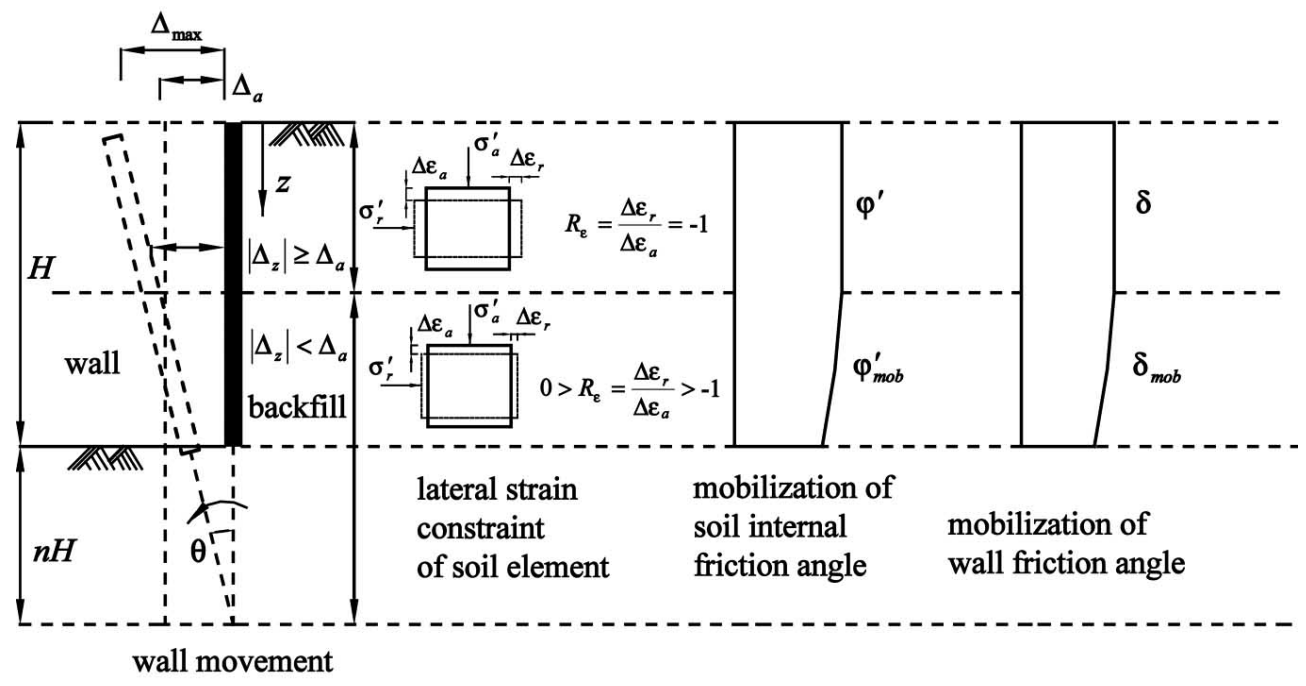

(b) RBT mode

Fig. (2). Schematic diagram of mobilization of frictional resistance for the wall under rotation mode: (a) RTT mode, (b) RBT mode. 
due to stress-dilatancy vary at different depths along the wall and adjust with the lateral strain constraint of the backfill. The internal friction angle and wall friction angle are partly mobilized. When $\triangle_{\mathrm{Z}} \leq-\triangle_{\mathrm{a}}, R_{\varepsilon}=-1$. At this time the soil is at the shear failure state and its shear resistance is fully mobilized. It is assumed that the soil internal friction angle and wall friction angle are both fully mobilized simultaneously. Therefore, when $R_{\varepsilon}=-1, \varphi_{\text {mob }}^{\prime}=\varphi^{\prime}$ and $\delta_{\mathrm{mob}}=\delta$. It can be also seen from Fig. (2b) that for the RBT mode, the amount of wall displacement at the top of the wall is larger than that at the bottom of the wall. Therefore, the lateral deformation of the backfill near the top of the wall is also larger than that at the lower part of the backfill. With the increase of the depth of the backfill, the proportion of compression deformation in the total deformation gradually increases and that of shear deformation gradually decreases, meaning that compression effect increases and stressdilatancy effect decreases. The mobilized frictional resistance gradually decreases with the backfill depth and the one at the lower part of the backfill is smaller than that of the upper part of the backfill. The mobilized friction angle at different depth can be determined by Eq. (2).

As is shown in Fig. (2a), for the RTT mode, if the top of the wall is selected as the coordinate origin $O(0,0)$, the wall displacement at a certain depth is given by the following equation:

$\Delta_{z}=(n H+z) \tan \theta$

in which $n$ is the parameter indicating the location of the center of the wall rotation.

In the same way, it can be seen from Fig. (2b) that for the RBT mode, the wall displacement at a certain depth is given by the following equation:

$\Delta_{z}=[(n+1) H-z] \tan \theta$

The relation between the strain increment ratio $R_{\varepsilon}$ and the wall displacement $\triangle_{\mathrm{z}}$ at the active side can be estimated by the formulas proposed by Zhang et al. (1998) [14]:

$$
R_{\varepsilon}=\left\{\begin{array}{lc}
-\left(\frac{\left|\Delta_{z}\right|}{\Delta_{a}}\right)^{a} & \left(-\Delta_{a} \leq \Delta_{z} \leq 0\right) \\
-1 & \left(\Delta_{z}<-\Delta_{a}\right)
\end{array}\right.
$$

in which $a$ is a constant changing within the ranges: $0<a<1$ and is recommended to take around 0.5.

The mobilized wall friction angle $\delta_{\text {mob }}$ changes with the lateral strain parameter $R$ and can be estimated by the following equations suggested by Zhang (1998) [14]:

$\delta_{m o b}=\left(\frac{1-R_{\varepsilon}}{2}\right)^{k_{1}} \cdot \delta$

in which $k_{1}$ is the exponent determined by tests and they can be assigned a value of unity, i.e., $k_{1}=1$, if the change in $\delta_{\text {mob }}$ with $R$ is assumed linear.

Based on the analysis of the test results of Matsuo et al. (1941, 1960\&1978) Ishii et al. (1960), Ichihara et al. (1973),
Fang et al. (1986), Ishibashi et al. (1987), and Sherif et al. (1982\&1984), it can be found that seismic earth pressures against rigid retaining structures under RTT mode consist of five components: (1) earth pressure induced by the soil weight, (2) earth pressure induced by the surcharge on the surface of the backfill, (3) residual earth pressure induced by the compaction of the backfill, (4) earth pressure induced by the inertial forces, (5) earth pressure induced by the soil arching effect. While that under RBT mode mainly consist of the former four.

The test results of Sherif et al. (1982\&1984) indicate that compaction will lead to the increase of the earth pressure $[16,17]$. This increment of earth pressure is called residual earth pressure. Sherif et al. (1984) suggested that, the residual earth pressure coefficient caused by compaction at $K_{0}$ state, denoted by $K_{\mathrm{rh} 0}$, can be estimated by the following equation [17]:

$$
K_{\text {rh. } .0}=5.5\left(\gamma_{\text {actual }} / \gamma_{\text {initial }}-1\right)
$$

in which $\gamma_{\text {actual }}$ is the actual unit weight of soil after compaction and $\gamma_{\text {initial }}$ is the unit weight due to dead weight of the backfill. In addition, their experimental results indicate that this part of earth pressure distributes linearly along the wall.

Based on the analysis of earth pressure model tests of Matsuo 1941, Ishii et al. 1960, Ichihara et al. 1973, Sherif et al. 1982\&1984, Zhang et al. (1998) pointed out that this part of residual earth pressure varies with the lateral strain constraint of the backfill. The following equation is proposed by Zhang et al. (1998) to determine the relation between the residual earth pressure coefficient and the strain increment ratio [15]:

$$
K_{r h}=K_{r h . o}\left(1+R_{\varepsilon}\right)^{m_{1}} \quad\left(-1 \leq R_{\varepsilon} \leq 0\right)
$$

in which $m_{1}$ is the parameter determined by experiments and can be taken as 1 approximately.

\section{FORMULATION OF THE METHOD}

\section{1. The Method for Rtt Mode}

Earth pressure induced by the soil weight, surcharge and inertial forces can be obtained by the analysis of the force equilibrium of the "intermediate soil wedge", whose concept is proposed by Zhang et al. (1998) [15]. In this paper, the method of horizontal differential element is employed to calculate the earth pressure distribution because the experimental results of Fang et al. (1986) and Ishibashi et al. (1987) indicate that earth pressure distribution against retaining structures with RTT mode is significantly nonlinear [7, 9]. $k_{\mathrm{h}}$ and $k_{\mathrm{v}}$ are used to denote the horizontal and vertical earthquake coefficients respectively. In seismic conditions, in addition to static loads of the soil weight $G$ and surcharge $q_{0}$, the soil wedge is also subject to $k_{\mathrm{h}} G, k_{\mathrm{v}} G, k_{\mathrm{h}} q_{0}$ and $k_{\mathrm{v}} q_{0}$. As is shown in Fig. (3), force equilibrium is made on a horizontal differential element taken from the soil wedge. The differential equation about $q$ is established according to force and moment equilibrium conditions. The equation is solved and then the earth pressure distribution is obtained 


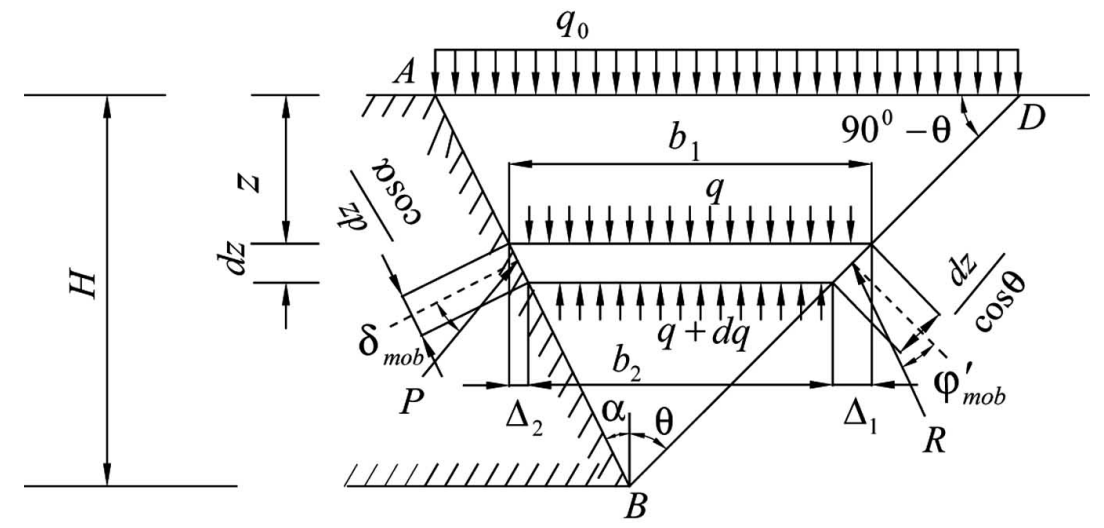

Fig. (3). Method for the level-layer analysis of intermediate soil wedge at the active side.

according to the relation between $p$ and $q$. The detail of derivation is not given here due to the length limitation of the paper.

The earth pressure distribution can be calculated by the following equation:

$$
\begin{aligned}
& p(z)=\frac{\lambda_{1} A_{2} \gamma}{\left(A_{1}+1\right)}\left[\frac{H^{\left(A_{1}+1\right)}}{(H-z)^{A_{1}}}-(H-z)\right] \\
& +\lambda_{2} k_{h} \gamma(H-z)+\lambda_{3} q_{0}\left(\frac{H}{H-z}\right)^{D}+K_{r h} \gamma z
\end{aligned}
$$

in which $K_{\mathrm{rh}}$ can be determined by Eq. (8). $\lambda_{1}, \lambda_{2}, \lambda_{3}, A_{1}, A_{2}$ and $D$ can be determined by the following equations:

$$
\begin{aligned}
& \lambda_{1}=\frac{1-\frac{2 \cos \alpha \sin \theta}{\sin (\theta+\alpha)}}{\frac{\cos \theta}{\sin (\theta+\alpha)}\left[\sin \left(\alpha+\delta_{m o b}\right)-\cos \left(\alpha+\delta_{m o b}\right) \tan \left(\theta+\varphi_{m o b}^{\prime}\right)\right]} \\
& \lambda_{2}=\frac{\tan \left(\theta+\varphi_{m o b}^{\prime}\right)}{\frac{\cos \theta}{\sin (\theta+\alpha)}\left[\cos \left(\alpha+\delta_{m o b}\right) \tan \left(\theta+\varphi_{m o b}^{\prime}\right)-\sin \left(\alpha+\delta_{m o b}\right)\right]} \\
& \lambda_{3}=\frac{\left[\left(k_{v}-1\right) \sin (\alpha-\theta)-2 k_{h} \cos \alpha \cos \theta\right]\left[1-k_{v}+k_{h} \tan \left(\theta+\varphi_{m o b}^{\prime}\right)\right]}{\cos \theta\left[\left(k_{v}-1\right) \sec \left(\theta+\varphi_{m o b}^{\prime}\right) \sin \left(\alpha+\delta_{m o b}-\theta-\varphi_{m o b}^{\prime}\right)-2 k_{h} \sin \left(\alpha+\delta_{m o b} \tan \left(\theta+\varphi_{m o b}^{\prime}\right)\right]\right.} \\
& A_{1}=1-\lambda_{1} B \\
& A_{2}=k_{h} \tan \left(\theta+\varphi_{r}^{\prime}\right)+1-k_{v}-\lambda_{2} k_{h} B \\
& B=\frac{\cos \theta}{\sin (\theta+\alpha)}\left[\sin \left(\alpha+\delta_{m o b}\right)+\cos \left(\alpha+\delta_{m o b}\right) \tan \left(\theta+\varphi_{m o b}^{\prime}\right)\right] \\
& D=1-\lambda_{3} \frac{\left[\tan \left(\theta+\varphi_{m o b}^{\prime}\right) \cos \left(\alpha+\delta_{m o b}\right)+\sin \left(\alpha+\delta_{m o b}\right)\right] \cos \theta}{\sin (\theta+\alpha)\left[\left(1-k_{v}\right)+k_{h} \tan \left(\theta+\varphi_{m o b}^{\prime}\right)\right]}
\end{aligned}
$$

The value of $\theta$ can be determined by the following equation:

$\left\{\begin{array}{l}\theta=\arctan S-\varphi_{m o b}^{\prime}, \arctan S-\varphi_{m o b}^{\prime}>0 \\ \theta=\pi-\left|\arctan S-\varphi_{m o b}^{\prime}\right|, \arctan S-\varphi_{m o b}^{\prime}<0\end{array}\right.$

$S=\frac{-R_{2}-\sqrt{R_{2}^{2}-4 R_{1} R_{3}}}{2 R_{1}}$

$R_{1}=\cos \alpha \sec \varphi_{m o b}^{\prime}\left\{-k_{h} \cos \left(\alpha+\delta_{m o b}\right) \sin \left(\alpha-\varphi_{m o b}^{\prime}\right) \tan \varphi_{m o b}^{\prime}\right.$ $\left.+\cos \left(\alpha-\varphi_{m o b}^{\prime}\right)\left[k_{h} \cos \left(\alpha+\delta-\varphi_{m o b}^{\prime}\right) \sec \varphi_{m o b}^{\prime}+\left(k_{v}-1\right) \cos \left(\alpha+\delta_{m o b}\right) \tan \varphi_{m o b}^{\prime}\right]\right\}$

$$
\begin{aligned}
& R_{2}=2 \cos \alpha\left[\left(k_{v}-1\right) \cos \left(\alpha+\delta_{m o b}\right) \sec \varphi_{m o b}^{\prime} \sin \left(\alpha-\varphi_{m o b}^{\prime}\right) \tan \varphi_{m o b}^{\prime}+\right. \\
& \left.k_{h} \sin \left(\alpha+\delta_{m o b}\right)\left(\cos \alpha+\sin \alpha \tan \varphi_{m o b}^{\prime}\right)\right] \\
& R_{3}=\cos \alpha\left\{\left(k_{v}-1\right) \cos \left(\alpha+\delta_{m o b}-\varphi_{m o b}^{\prime}\right) \sec ^{2} \varphi_{m o b}^{\prime} \sin \left(\alpha-\varphi_{m o b}^{\prime}\right)+\right. \\
& \left.\sin \left(\alpha+\delta_{m o b}\right)\left[k_{h} \sec \varphi_{m o b}^{\prime} \sin \left(\alpha-\varphi_{m o b}^{\prime}\right)-\left(k_{v}-1\right)\left(\cos \alpha+\sin \alpha \tan \varphi_{m o b}^{\prime}\right)\right]\right\}
\end{aligned}
$$

in which $\varphi_{\text {mob }}^{\prime}$ and $\delta_{\text {mob }}$ can be determined by Eq. (2), (3), (5) and (6). $\alpha$ is the inclination angle of the wall with the vertical direction.

The mechanism of earth pressure induced by soil arching is rather complicated. Soil arching induces stress transition in the backfill and this is realized by the mobilization of shear strength of the soil. Experimental results of Fang et al. (1986) indicate that the range of the arching zone is from the top of the backfill to a depth about $1 / 4$ to $1 / 3$ the height of the wall. Therefore, the increase of earth pressure can be reflected by multiplying the mobilized internal friction angle of the backfill in the arching zone by a correction coefficient. The denser the backfill is, the stronger the soil arching effect is. This leads to the enlargement of the earth pressure in the arching zone. With reference to Gong et al. (2006) [12], a correction coefficient $\varepsilon$ is adopted to reflect the effect of soil arching on earth pressure. The mobilized friction angle of backfill in the arching zone can be determined by the following equation:

$$
\varphi_{m o b}^{\prime}=\varepsilon \arcsin \left[\frac{\sin \varphi^{\prime}\left(1-R_{\varepsilon}\right)}{2-\sin \varphi^{\prime}\left(1+R_{\varepsilon}\right)}\right]
$$

in which $\varepsilon$ can be estimated by experiments and is about 0.2 to 0.7 . The denser the backfill is, the smaller the $\varepsilon$-value is.

\subsection{The Method for Rbt Mode}

According to the experimental results of Terzaghi and Tschebotarioff (1962), Sherif et al. (1984), the earth pressure distribution against rigid retaining walls under RBT mode is nearly linear $[17,18]$, so the earth pressure distribution can be obtained by substituting the internal friction angle and wall friction angle by $\varphi_{m o b}^{\prime}$ and $\delta_{m o b}$ respectively in Mononobe-Okabe solution, which can be expressed by the following equation:

$p(z)=K_{E} \cdot\left(1-k_{v}\right) \cdot\left(\gamma z+q_{0}\right)+K_{r h} \gamma z$ 
$K_{E}=\frac{\cos ^{2}\left(\varphi_{m o b}^{\prime}-\alpha-i\right)}{\cos i \cos ^{2} \alpha \cos \left(\delta_{m o b}+\alpha+i\right)\left[1+\sqrt{\frac{\sin \left(\varphi_{m o b}^{\prime}+\delta_{m o b}\right) \sin \left(\varphi_{m o b}^{\prime}-i\right)}{\cos \left(\delta_{m o b}+\alpha+i\right) \cos \alpha}}\right]^{2}}$

$i=\arctan \left(\frac{k_{h}}{1-k_{v}}\right)$

in which $\varphi_{\text {mob }}^{\prime}$ and $\delta_{\text {mob }}$ can be determined by Eq. (2), (4), (5) and (6). $\alpha, k_{\mathrm{h}}$ and $k_{\mathrm{v}}$ have the same meanings as have been defined previously.

\section{DISCUSSION}

Corresponding computer code is written to calculate the earth pressure distribution based on the methodology developed above. The seismic earth pressure coefficient $K$ is defined as the ratio of total earth thrust to $\gamma H^{2} / 2$. Variation of seismic earth pressure coefficients with internal frictional angle, horizontal earthquake coefficient, the rotation angle of the wall and wall friction angle is shown in Fig. (4). It can be seen from Fig. (4) that the earth pressure coefficient decreases with the amount of rotation of the wall and the increase of horizontal earthquake coefficient and wall friction angle. The earth pressure coefficient for the rigid retaining wall under RTT mode is little larger than that under RBT mode due to the soil arching effect. Variation of $K$ with the parameter $n$ is shown in Fig. (5). It can be seen from Fig. (5) that the earth pressure coefficient decreases with the increase of $n$. This is because when the rotation angle $\theta$ keeps the constant, the wall displacement at a certain depth increases with the increase of $n$, which in turn results in the decrease of the earth pressure coefficient.

\section{EXPERIMENTAL VERIFICATION OF THE METHOD}

The comparison of the results calculated by the proposed method and those measured by Fang et al. (1986) and Ishibashi et al. (1987) is shown in Fig. (6). According to the test results of Fang et al. (1986), the parameters for the calculation by the RTT method are: $\gamma_{\text {initial }}=15.21 \mathrm{kN} / \mathrm{m}^{3}$, $\gamma_{\text {actual }}=15.83 \mathrm{kN} / \mathrm{m}^{3}, \quad \triangle_{\mathrm{a}}=0.0003 \mathrm{H}, \quad \delta=\varphi^{\prime} / 2, \quad \varphi_{\text {triaxial }}^{\prime}=34.9^{\circ}$, $\varepsilon=0.6, H=1.02 \mathrm{~m}, k_{\mathrm{h}}=k_{\mathrm{v}}=0, n=0$. It can be seen from Fig. (6a) that for the rigid retaining structure under RTT mode, the earth pressure distribution is obviously nonlinear. The soil arching effect in the zone from the backfill surface to a depth
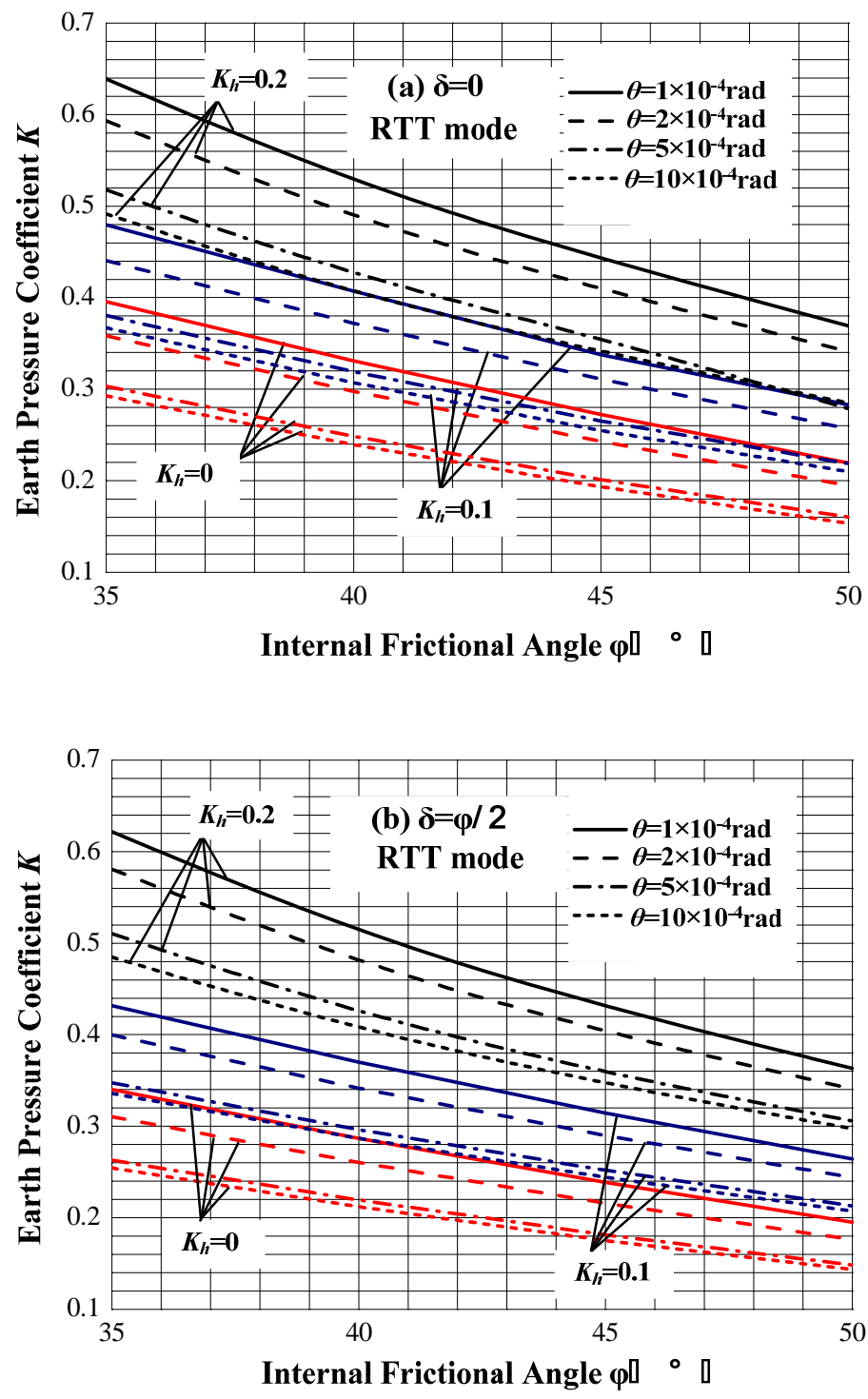
Fig. (4). contd....
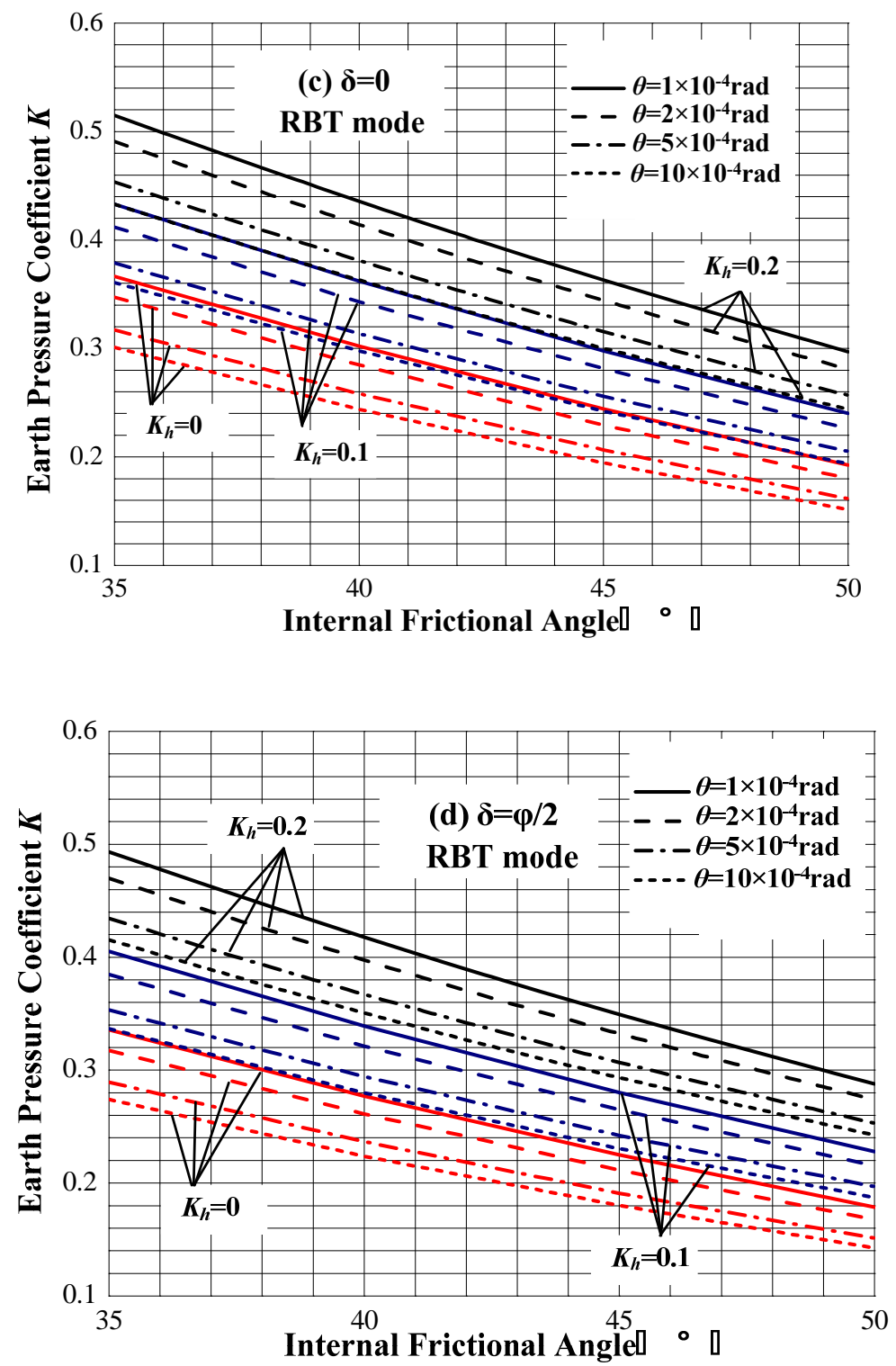

Fig. (4). A chart showing the variation of earth pressure coefficient with internal friction angle, rotation angle of wall, horizontal earthquake coefficient and wall friction angle $\left(n=0, k_{v}=0\right)$.

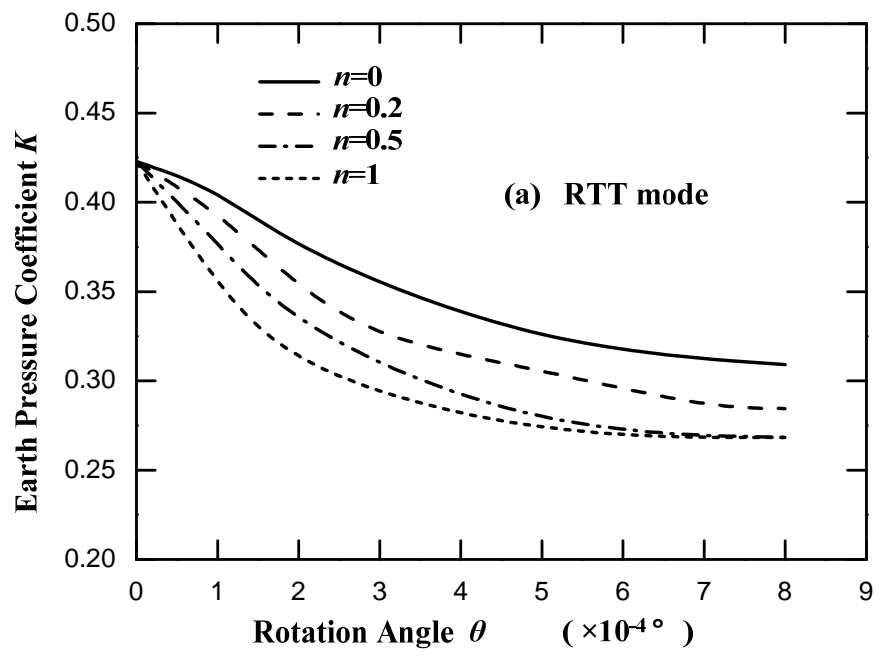




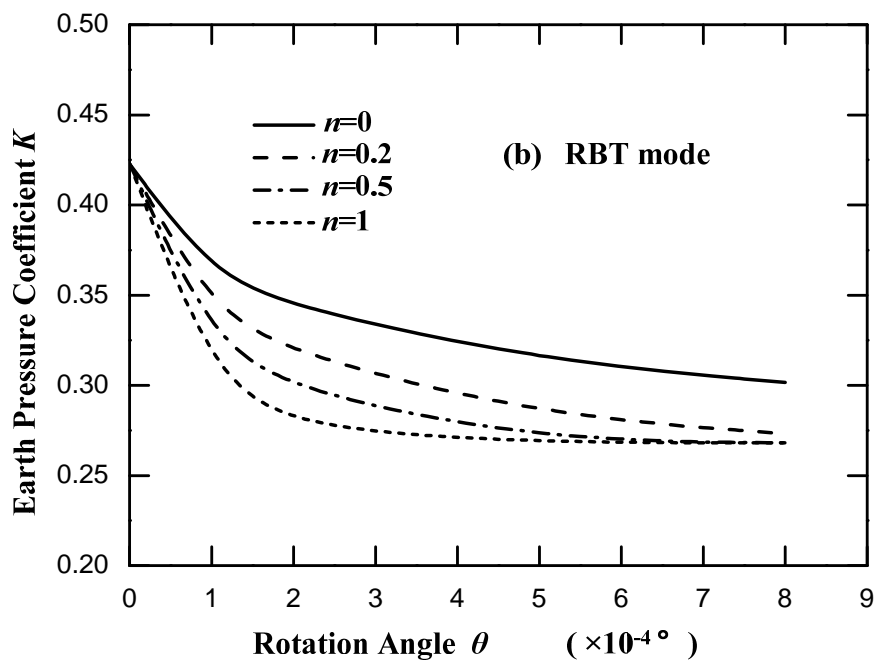

Fig. (5). contd....

Fig. (5). A chart showing the variation of earth pressure coefficient with the parameter $n\left(k_{h}=0.1, k_{v}=0, \varphi^{\prime}=40^{\circ}, \delta=0\right)$
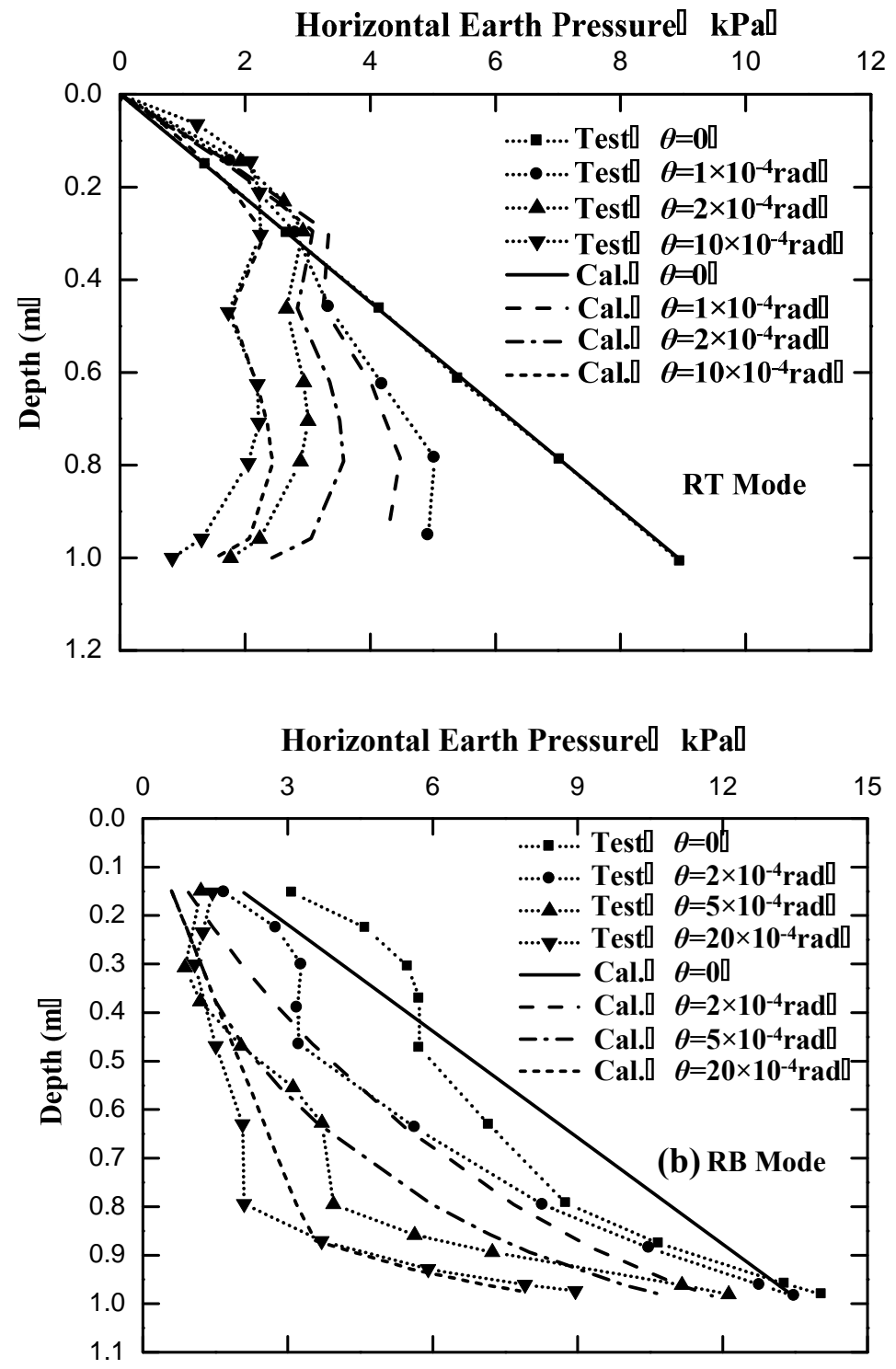

Fig. (6). Comparison of calculation results and experimental results of Fang et al. (1986) and Ishibashi et al. (1987): (a) RT mode (b) RB mode. 
ranging from $1 / 4$ to $1 / 3$ of the wall height results in the increase of the earth pressure in this part. The earth pressure decreases in the lower part of the backfill due to the friction at the bottom of the wall. Therefore, the earth pressure distribution is the one shown in Fig. (6a). With the increase of the wall displacement, the soil arching effect gradually increases. The effectiveness of the method proposed for RBT method is also verified by the experimental results of Ishibashi et al. (1987). According to the test results, the parameters for the calculation by the RBT method are: $\gamma_{\text {initial }}=15.21 \mathrm{kN} / \mathrm{m}^{3}, \gamma_{\text {actual }}=16.43 \mathrm{kN} / \mathrm{m}^{3}, \triangle_{\mathrm{a}}=0.0003 H, \delta=\varphi^{\prime} / 2$, $\varphi_{\text {triaxial }}^{\prime}=40.1^{\circ}, H=1.02 \mathrm{~m}, k_{\mathrm{h}}=0.215, k_{\mathrm{v}}=0, n=0$. It can be seen from Fig. (6) that the results obtained by the method proposed in the paper is basically consistent with the experimental results of Fang et al. (1986) and Ishibashi et al. (1987), showing the effectiveness of the method.

\section{CONCLUSIONS}

In this paper, the formation mechanism of earth pressures against rigid retaining structures under rotation mode is revealed. It is found out that under rotation mode due to the variation of lateral strain constraint along the wall, the proportion of compression to stress-dilatancy effect varies at different depths of the backfill. Therefore, the mobilized friction angle varies with different levels of compressiondilatancy coupling effect under different lateral strain constraints because of the rotation of the wall. On this basis a new method is developed for the evaluation of seismic earth pressures against rigid retaining structures with such mode and corresponding formulas are derived. Especially, for the RTT mode, the nonlinear distribution of earth pressure is considered by employing the method of horizontal differential element. Corresponding computer programs are written for the computation of seismic earth pressure distribution against rigid retaining structures with rotation mode. The method proposed in this paper has advantages over Mononobe-Okabe method because it can take into account of the effect of the amount and mode of wall movement on the earth pressure. Finally, the effectiveness of the proposed method is confirmed experimentally.

\section{ACKNOWLEDGEMENTS}

The authors wish to thank the Youth Project Supported by Natural Science Basic Research Plan in Shaanxi Province of China (Program No. 2010JQ7002) and China Postdoctoral Science Foundation funded project (Program No. 20100471591) for their financial support.

\section{DISCLOSURE}

The major portion of this manuscript included in this article has been previously published in Advanced Materials Research (Volumes 168-170, 2011). This article is extended version/current knowledge on "Evaluation of Earth Pressures against Rigid Retaining Structures with RTT Mode” paper.

\section{REFERENCES}

[1] K. Terzaghi, "Large retaining wall tests", Engineering News Record, vol. 112, pp.136-140, 1934.

[2] H. Matsuo, "Experimental study on the distribution of earth pressure acting on a vertical wall during earthquakes", Journal of the Japan Society of Civil Engineers, vol. 27, no. 2, 1941.

[3] H. Matsuo, and S. Ohara, "Lateral earth pressure and stability of quay walls during earthquakes", In: Proc. of $2^{\text {nd }}$ World Conference on Earthquake Engineering, Tokyo, 1960, vol. 1, pp. 165-183.

[4] M. Matsuo, S. Kenmochi, and H. Yagi, "Experimental study on earth pressure of retaining wall by field tests", Soils and Foundations, vol. 18 , no. 3, pp. 27-41, 1978.

[5] Y. Ishii, H. Arai, and H. Tsuchida, "Lateral earth pressure in an earthquake", In: Proceedings of the $2^{\text {nd }}$ World Conference on Earthquake Engineering, Tokyo, 1960, vol. 1, pp. 211-230.

[6] M. Ichihara, and H. Matsuzawa, "Earth pressure during earthquake", Soils and Foundations: vol.13, no.4, pp. 75-86, 1973.

[7] Y. S. Fang, and I. Ishibashi, "Static earth pressures with various wall movements", Journal of Geotechnical Engineering, ASCE, vol. 112, no. 3, pp. 317-333, 1986.

[8] Y. S. Fang, T. J. Chen, and B. F. Wu, "Passive earth pressures with various wall movements", Journal of Geotechnical Engineering, vol. 120, no.8, pp.1307-1323, 1994.

[9] I.. Ishibashi, and Y. S. Fang, "Dynamic earth pressures with different wall movement modes", Soils and Foundations, vol. 27, no. 4, pp. 11$22,1987$.

[10] G. A. Dubrova, "Interaction of soil and structures", Rehnoy Transport, Moscow, U.S.S.R. 1963.

[11] M. F. Chang, "Lateral earth pressure behind rotating walls", Canadian Geotechnical Journal, vol. 34, no.4, pp.498-509, 1997.

[12] C. Gong, J. L. Yu,z R. Q. Xu, and G. Wei, Calculation of earth pressure against rigid retaining wall rotating outward about base, Journal of Zhejiang University (Engineering Science), vol. 39, no.11, pp. 16901694, 2005.

[13] C. Gong, G. Wei, and R. Q. Xu, "Earth pressure against rigid retaining wall rotating about top", Rock and Soil Mechanics, vol. 27, no. 9 , pp. 1588-1592, 2006.

[14] J. M. Zhang, Y. Shamoto, and K. Tokimatsu, "Evaluation of earth pressure under any lateral deformation", Soils and Foundations, vol. 38, no.1, pp. 15-33, 1998.

[15] J. M. Zhang, Y. Shamoto, and K. Tokimatsu, "Seismic earth pressure theory for retaining walls under any lateral displacement", Soils and Foundations, vol. 38, no. 2, pp. 143-163, 1998.

[16] M. Sherif, I. Ishibashi, and C. D. Lee, "Earth pressures against rigid retaining walls", Journal of Geotechnical Engineering, ASCE, vol.108, (GT5), pp. 679-695, 1982.

[17] M. A. Sherif, Y. S. Fang, and R. I. Sherif, " $K_{\mathrm{a}}$ and $K_{0}$ behind rotating and non-yielding walls", Journal of Geotechnical Engineering, ASCE, vol. 110, no. 1, pp. 41-56, 1984.

[18] G. P. Tschebotarioff, "Retaining structures", In: G.A. Leonards, Ed., Foundation Engineering, McGraw-Hill, New York NY, 1962, pp. 438-524. 